\title{
Горлова Е.В. \\ Выявление основных мотивации отказа от рождения детей у современного «чайлдфри»
}

Астраханский государственный университет

(Россия, Астрахань)

doi:10.18411/spc-01-11-2017-04

idsp: 000001:spc-01-11-2017-04

За последние пятьдесят лет наблюдается значительный сдвиг в модели рождаемости в развитых странах, произошедший главным образом в результате достижений в области контрацепции, образования и гендерного равенства. Новые реалии ставят перед современными людьми множество вызовов, одним из которых является вопрос продолжения рода человеческого, а именно желания рождения детей. Людей, добровольно выбравших жизнь без детей, отказавшихся от рождения детей или же тех, кто сознательно не хочет (или больше не хочет) обременять себя совместной жизнью с детьми принято называть «чайлдфри» (от англ. childfree - свободные от детей), а их объединившихся единомышленников - «группами чайлдфри», «сообществом чайлдфри» и т.п.Целью данной статьи является попытка сформировать примерный образ современного «чайлдфри». Методологией исследования является выявление основных мотивации отказа от рождения детей у мужчин и у женщин.

На протяжении последних десятилетий этот феномен вызывает устойчивый массовый интерес, как в научной среде, так и в СМИ,поскольку у данного нового видения своей гендерной роли в обществе появляются как ярые сторонники, так и ярые противники, считая его социальным паразитом. Этим и объясняется актуальность нашего исследования.

Научная и публицистическая литература, посвящённая изучению «чайлдфри», весьма разнообразна. Данный феномен исследуют историки, социологи культуры, социальные антропологи, религиоведы, философы, культурологи, специалисты по маркетинговым исследованиям и мн. др. При изучении причинно-следственных связей появления «чайлдфри», нередко встречается упоминание работ Д. Кэлхуна, который в 60-70-е гг. XX в. проводил опыты по созданию идеального мира на примере мышиной стаи [1]. Основная идея данных экспериментов заключалась в том, что для испытуемыхбыл создан в замкнутых условиях т.н. мышиный рай, в котором не было необходимости беспокоиться о болезнях, воде и еде. Изначальный демографический взрыв постепенно замедлялся и грызуны стали проявлять девиантное поведение. Так, пассивные самцы все меньше и меньше тяготели к самкам, зачастую молодые особи становились «отверженными», т.к. их агрессивно подавляли старшие и более опытные самцы, которые не умирали вследствие недостатка пищи или болезней. У них происходил психологический слом, и они уже не могли заботиться ни о себе, ни о беременных самках.Д. Кэлхун определяет этот этап отказа от своих поведенческих обязанностей т.н. «смертью духа». У самок, в свою очередь, стала проявляться нервозность и агрессия, как к членам стаи, так и к собственным детенышам.Они стали отказываться от спаривания и деторождения и становились «отшельниками».Таким образом, в ходе эксперимента стали появляться т.н. «красивые» мыши (у них отсутствовали шрамы от драк), которые ели, пили, избегали каких-либо конфликтов,отказывались не только от своих социальных обязанностей, но и от желания к размножению. В ходе эксперимента смертность молодняка достигла ста 
процентов, более взрослые особи умирали от старости, количество беременностей постепенно приблизилось к нулю, что и привело в свою очередь к вымиранию популяции [1].

Конечно,результаты данного эксперимента вызывают определенные опасения, особенно применительно к современным гендерным тенденциям. Однако, не будем забывать, что эксперимент проводился над животным миром, а мир людей более сложный и с моральной и физиологической точек зрения. Тем не менее, Д. Кэлхун выделил интересный этап «смерти духа», когда сломленные мыши осознанно отказывались от воспроизведения потомства. К сожалению, этот этап предшествовал следующему этапу - смерти физической. Таким образом, соотнося результаты эксперимента Д. Кэлхуна с интересующей нас научной проблематикой, мы можем акцентировать внимание на некоторых исследовательских проблемах. Так, если современная женщина и современный мужчина, подверженные идеям «чайлдфри», добровольно отказываются от воспроизведения потомства, то:1. Не связан ли этот отказ со «слишком» хорошими условиями жизни (т.н. мышиным раем)?; 2. Существует ли некий аналог «смерти духа» у людей, влияющий на приверженность к идеологии «чайлдфри»?Поскольку наиболее широко данное направление представлено в США, проанадизируем образ представителей «чайлдфри» на примере американского сообщества.

Логично предположить, что среди последователей «чайлдфри» существуют различные причины отказа от деторождения. Исследователи Д.Абма и Г. Мартинес [2]отмечают, что среди бездетных американских женщин в возрасте от 35 до 44 лет, распределение причин отказа от рождения детей было следующим: $42 \%$ добровольный отказ и 28\% - непроизвольный отказ (в силу каких-либо причин), 30\% классифицированы как временно бездетные (те, кто еще не имел детей, но планирует появление ребенка в будущее).

Многочисленные исследователи (Л. Брин, С.Джеффриз, Д. Дойл, К. Коннерт, Д. Пули и мн. др.) [4;9] отмечают, что деление только на добровольный и непроизвольный отказ от рождения детей может быть слишком упрощенным и не выявить всех причин данного решения, так как путь к бездетности (термин «добровольно бездетные»в данном контексте применяется только к приверженцам идей «чайлдфри» и ни в коей мере не относится к женщинам, желающим завести ребенка, но не имеющим на то возможностей) часто включает в себя комбинациюкак собственного выбора, так и непроизвольных факторов. Исследования Й. Вееверс[15] показывают, что наиболее сильную приверженность к идее оставаться бездетнымипроявляют те, кто принимает данное решение в достаточно молодом возрасте. Также автор отдельно выделяет тех, кто откладывал вопрос о рождении ребенка, предполагая, что у них появится ребенок в подходящее для этого время, но, в итоге, так и не решился на это.

Авторы Е. Грей, А. Еванс, А. Реимондос, А. Фернхам отмечают, что характеризовать человека как полностью отказавшегося от рождения детейможно только в случае наступления менопаузы у женщин или стерилизации у обоих полов [6; 7]. Вполне логично, что значительная часть тех, кто выражал намерения остаться бездетным может позже изменить свое мнение. Таким образом, мы можем говорить о возможной погрешности в исследованиях, посвященных «чайлдфри».

Помимо жизненных обстоятельств на выбор человека также влияют и многочисленные социальные факторы. Рассмотрим последователей «чайлдфри» с учетом влияния данных факторов. Так, в ходе своего исследования, Д. Абма и Г. 
Мартинес[2] пришли к выводу, что женщины «чайлдфри» имеют тенденцию быть более образованными по сравнению с женщинами, которые уже имеют детей или только желают стать родителями. Также, авторы отмечают, что добровольно бездетные женщины имеют относительно более высокие доходы, которые они используют для совершенствования своих профессиональных навыков и для улучшения условий проживания в городской среде.Авторы В. Варен и Х. Палс[16] отмечают, что чем больше женщины вкладывают средства в образование, тем более они подвержены идеям «чайлдфри», что не так выражено у мужского населения. Исследователь С. Каназава[10]также отмечает, что данное соотношение у мужчин не нашло схожего результата.

Интересно также рассмотреть ценностные ориентации последователей идей «чайлдфри». Исследователи (Д. Абма, В. Варен, Г. Мартинес, Х. Палс)[2; 16]сходятся во мнении, «чайлдфри» имеют тенденцию в своих привычках быть менее традиционными и менее консервативными, с более эгалитарным отношением к обеспечению гендерного равенства. Кроме того, как отмечают С. Стоберт и А. Кемени[14] «чайлдфри»чаще другого населения могут быть или нерелигиозными или атеистами.

Помимо социальной составляющей, для нас также представляет интерес мотивация стать «чайлдфри». Так, один из самых популярных доводов большинства «чайлдфри» является стремление к независимости и свободе[5]. В рамках исследования мотивациидобровольно бездетных 1979г. С. Хоусекнечт[8]отмечает, что свобода от ответственности по уходу за ребенком была упомянута в качестве обоснования в $79 \%$. В опросе 2009 г. также более 80 \% респондентов (мужчины и женщины «чайлдфри» в возрасте до 40 лет)заявили о том, что прежде всего они ценят свободу и независимость[13].Таким образом, мы можем констатировать, что несмотря на тридцатилетнюю разницу в исследованиях главная мотивация осталась неизменной.

Интересным представляется тот факт, что общее представление о том, что«чайлдфри» не любят детей, относится лишь к четверти всех опрошенных и не является повсеместным. Большинство же респондентов заявили о том, что они испытывают определенный дискомфорт в окружении детей или же у них отсутствует интерес к ним[13]. На наш взгляд, если рассмотреть данную статистику с позиции российского менталитета, то дискомфорт и отсутствие интереса как раз и можно назвать нелюбовью к детям. Однако другие представители «чайлдфри» могут любить детей и наслаждаться регулярными контактами с ними посредством работы или семьи. По мнению исследователей, такие контакты достаточно важны для человека, особенно для женщин, которые чувствуют, что у них не будет детей.Таким образом, они удовлетворяют свой материнский инстинкт или желание быть родителями[5].

Согласно ряду исследований, стереотип, что большинство «чайлдфри» отказываются от детей специально, чтобы сосредоточиться на своей карьере, не нашел подтверждения[5; 12]. Данную мотивацию указало лишь незначительное меньшинство исследователей. Финансовые же проблемы, связанные с рождением и воспитанием ребенка, волнуют больше мужчин, чем женщин[5; 12]. Популярной причиной отказа от детей стала идея о более хороших отношениях с партнером, что является противоположностью традиционныхвзглядов на супружескую жизнь[5].

Результаты одного из последних исследований, проведенных в 2015г. М. Ависон и А. Фернхам[3], показывают, что современного «чайлдфри» в сравнении с человеком имеющим/желающим иметь детей можно характеризовать как не столь религиозного и 
более склонного к либеральным политическим взглядам. Авторы полагают, что стремление быть родителем отрицательно соотносится с независимостью и положительно с уступчивостью и религиозностью. Респонденты, которые решили не иметь детей,будучи вюношеском периоде,были более независимы в своих религиозных и политических взглядах, нежели те, кто пришел к «чайлдфри» в более зрелом возрасте.М. Ависон и А. Фернхам[3]отмечают, что стремление сохранить свою независимость и свободу было самой популярной мотивацией среди респондентов, повторив предыдущие исследования (С. Хоусекнечт1979 г., Л. Скотт 2009 г. и др.) и укрепив вывод, что данные критерии являются основным мотивационным выбором респондентов.

В ходе проведенного исследования мы можем охарактеризовать современного среднестатистического «чайлдфри» как человека: с высоким материальным и социальным статусом, хорошим образованием, либеральными взглядами, не религиозного, единственного ребенка в семье (воспитывался без братьев и сестер), с добровольной позицией относительно наличия детей.

Отвечая на поставленные вначале исследования вопросы, констатируем, что уровень жизни «чайлдфри» порой выше уровня людей с детьми, что идеи «чайлдфри» больше распространены в развитых станах, что это добровольный выбор человека, зачастую не связанный с какими-либо психологическими травмами или сломами. Таким образом, мы не нашли доказательств, что «чайлдфри» живут в определенном «мышином рае», однако, вполне очевидно, что популярность данных идей напрямую зависит от уровня комфорта современного человека. Также мы не нашли подтверждения идее о психологическом сломе, повлиявшим на убеждения последователей «чайлдфри».Наоборот, это осознанный выбор человека, привыкшего жить согласно своим жизненным принципам. Отметим, чтов ходе проведенной исследовательской работы, мы встречали упоминание о незначительном количестве людей, перенесших определенную душевную травму, что предопределило их выбор в пользу «чайлдфри». Однако, это не является доминантой в выборе изучаемого образа жизни.

Подчеркнём, что данное исследованиезатрагивает лишь часть вопросов, связанных с избранной проблематикой. Представленные изыскания раскрывают ряд направлений для дальнейшего изучения «чайлдфри» как нового феномена современного общества. Пугающее распространение этих идей говорит об их паразитарном влиянии на социум. Изучение обозначенной проблемы должно стать предметом более детализированного исследования, связанного с вопросом готовности общества к популяризации данного социального паразита.

Статья написана при финансовой поддержке Российского гуманитарного научного фонда, проект № 15-33-01319 «Семья и сочиальные паразиты»».

$$
* * *
$$

1. Эксперимент «Вселенная-25»: как рай стал адом - 21.11.14 - [Электронный ресурс] - Режим доступа : // http://www.cablook.com/mixlook/eksperiment-vselennaya-25-kak-raj-stal-adom/, свободный.

2. Abma, J.C., Martinez, G.M. Childlessness among older women in the United States: Trends and profiles // Journal of Marriage and Family. 2006. № 68(4). C. 1045-1056.

3. Avison, M., Furnham, A. Personality and voluntary childlessness // Journal of Population Research. 2015. № Vol. 32. C. 45-67.

4. Doyle, J., Pooley, J. A., Breen, L. A phenomenological exploration of the childfree choice in a sample of Australian women // Journal of Health Psychology. 2013. № 18(3). C. 397-407. 
5. Duxbury, L., Medhill, J., Lyons, S. Childfree by choice: A study of childfree women in North America Summary report. Centre for Research and Education on Women and Work, Ottawa, Canada. 2005.

6. Furnham, A. Choosing to Be Child-free. Why do some people not want to have children: to be childless? -

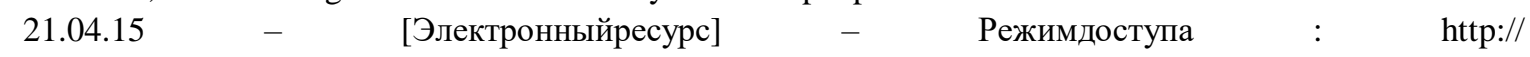
http://www.psychologytoday.com/blog/sideways-view/201504/choosing-be-child-free, свободный.

7. Gray, E., Evans, A., Reimondos, A. Childbearing desires of childless men and women: When are goals adjusted? // Advances in life course research. 2013. №18(2). C. 141-149;

8. Houseknecht, S.K. Timing of the decision to remain voluntarily childless: Evidence for continuous socialization // Psychology of Women Quarterly. 1979. № 4(1). C. 81-96.

9. Jeffries, S., Konnert, C. Regret and psychological well-being among voluntarily and involuntarily childless women and mothers // The International Journal of Aging and Human Development. 2002. № 54(2). C. 89-106.

10. Kanazawa, S. Intelligence and childlessness // Social Science Research. 2014. № 48(3). C. 157-170.

11. Kiernan, K. E. Who remains childless // Journal of Biosocial Science. 1989. № 21(4). C. 387-398.

12. Maher, J., \&Saugeres, L. To be or not to be a mother? Women negotiating cultural representations of mothering // Journal of Sociology. 2007. № 43(1). C. 5-21.

13. Scott, L. Two is enough: A couple's guide to living childless by choice. Berkley, California: Seal Press.2009.

14. Stobert, S., Kemeny, A. Childfree by choice // Canadian Social Trends. 2003. № 69. C. 7-10.

15. Veevers, J. E. Voluntarily childless wives; an exploratory study // Sociology and Social Research. 1973. № 57(3). C. 356-366.

16. Waren, W., Pals, H. Comparing characteristics of voluntarily childless men and women // Journal of Population Research. 2013. № 30(2). C. 151-170. 